\title{
Anthropic Principle Observed in the Material Properties of Fe
}

\author{
Yoshiharu Mae $^{1}$ \\ ${ }^{1}$ Maetech, Saitama, Japan \\ Correspondence: Yoshiharu Mae, Maetech 685-8, Mimuro, Midori-ward, Saitama-city, 336-0911, Japan. E-mail: \\ yoshimae@hotmail.com
}

Received: May 14, 2017

Accepted: May 24, 2017

Online Published: June 5, 2017

doi:10.5539/jmsr.v6n3p11

URL: https://doi.org/10.5539/jmsr.v6n3p11

\begin{abstract}
The melting temperature of $\mathrm{Fe}$ is $1808 \mathrm{~K}\left(1535^{\circ} \mathrm{C}\right)$. If it were higher than that, the ancient people could neither produce iron products, nor achieve the civilization. When the melting temperature of $\mathrm{Fe}$ is observed on the periodic table, it seems that the melting temperature is lowered intentionally and unnaturally. It can be suspected to be a sort of the anthropic principle. Fe belongs to the gulf elements, when the melting temperature is plotted on the TC-YM diagram. The gulf elements show the moderate melting temperatures totally. Moreover, $\mathrm{Fe}$ is also located on the quadrant of the large abundance on the TC-YM diagram. Fe is also located at the position in the TC-YM diagram, which shows relatively small ionization tendency, which means easy smelting. Fe is also located at the position between the straight line of refractory metals of bcc structure and $\mathrm{Ni}$ of fcc structure, which leads to the crystal structure of $\mathrm{Fe}$ to be bcc structure at lower temperature and fcc structure at high temperature.

These advantages in the properties of Fe come from its exquisite position of Fe on the TC-YM diagram. These can be thought an anthropic principle in Fe.
\end{abstract}

Keywords: anthropic principle, Fe, melting point, abundance, ionization tendency, Young's modulus, thermal conductivity

\section{Introduction}

Every metallic element melts at each melting temperature, but nobody knows how each melting temperature is decided. The melting point of iron is $1808 \mathrm{~K}\left(1535^{\circ} \mathrm{C}\right)$. This temperature was essentially unachievable during the ancient time. Instead, iron was produced by heating a piece of bloom in a charcoal furnace near $1373 \mathrm{~K}\left(1200^{\circ} \mathrm{C}\right)$, which was attainable for ancient people (Hummel, 1998). But, if the melting point of iron were higher than 1808K $(1535 \mathrm{~K})$, this heating temperature would be higher than $1373 \mathrm{~K}\left(1200^{\circ} \mathrm{C}\right)$, consequently, iron making would be impossible. The melting point $1808 \mathrm{~K}(1535 \mathrm{~K})$, therefore, should have the substantial meaning.

Figure 1 shows the variation of melting temperature of elements at each periodic number with increasing group number. Mountain-like distributions with the peak at the $6^{\text {th }}$ group number are seen. But after $7^{\text {th }}$ group, melting temperatures fall abruptly, especially at $4^{\text {th }}$ period elements, such as Mn, Fe, Co. Essentially, it should follow such a trend as shown by a dotted line. But the real melting temperature of Fe including $\mathrm{Mn}$ and $\mathrm{Co}$ is lower than the dotted line as if the top of the mountain were cut off. Such a low melting temperature of Fe may be a sort of the anthropic principle. The anthropic principle is that the nature is formed to be convenient for the existence of the mankind (Crossman, 2008).

The reasons why and the way how the melting temperature of iron is reduced are discussed here. And the ways how the other advantages of Fe are brought are discussed also.

\section{Definition of the Gulf Elements}

The author proposes to represent metallic and semi-metallic elements graphically, to enable their nature to be interpreted in more detail (Mae, 2016). The main characteristics of metallic elements are their crystal structures and the presence of free electrons. The Young's modulus and thermal conductivity are good indicators of the lattice strength and characteristics of free electrons, respectively. Each element is plotted on a diagram with thermal conductivity on the abscissa and Young's modulus on the ordinate.

The Young's modulus is generally thought to be an engineering factor, but it is a physically fundamental factor: The Young's modulus is proportional to the gradient of the tangent of the curve of the Condon-Morse force between atoms at an equivalent atomic distance, i.e., proportional to the second-order differential of the binding 
potential between two atoms at equivalent atomic distance (Hayden, Moffat, Wullf, 1965). Therefore, the Young's modulus is a good index to represent the binding state of atoms. Thermal conductivity can be considered to be related to the mobility of free electrons in atoms. This is also a physically fundamental factor. A diagram with thermal conductivity on the abscissa and Young's modulus on the ordinate (TC-YM diagram), therefore, can reflect the essential properties of atoms of the metallic and semi-metallic elements.

The author applied this diagram to the solubility problem of elements in metals and introduced the general law of solubility (Mae, 2016).

In this study, the same diagram was applied to the properties of iron. Figure 2 shows the distribution of all elements on the TC-YM diagram.

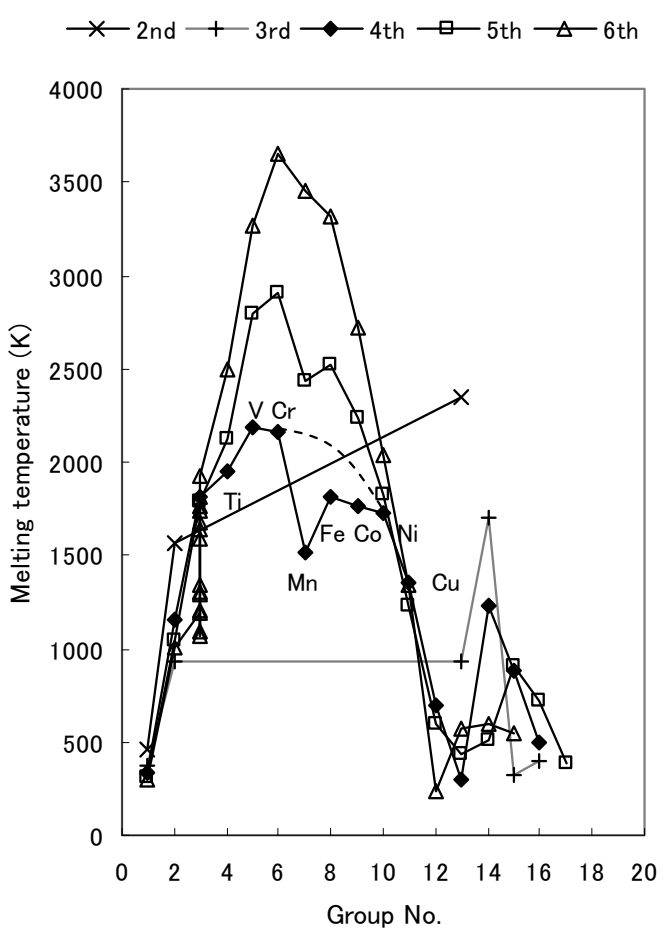

Figure 1. Melting temperatures of elements with the group number of the periodic table

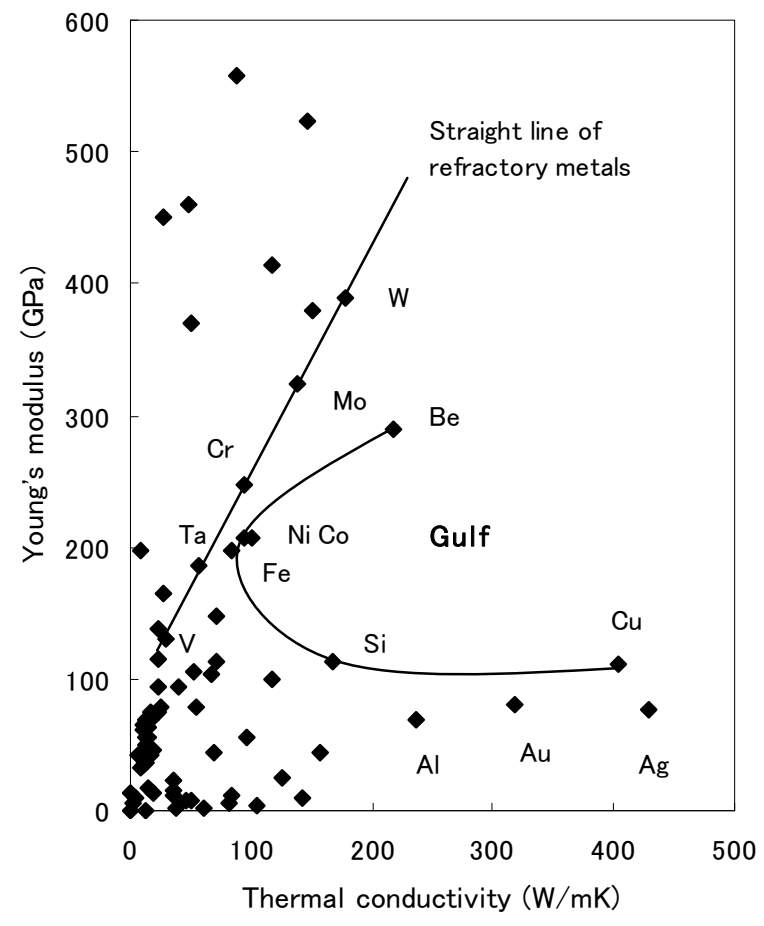

Figure 2. Positions of the gulf elements $\mathrm{Be}, \mathrm{Ni}, \mathrm{Co}$, $\mathrm{Fe}, \mathrm{Si}$ and $\mathrm{Cu}$ on the TC-YM diagram

The elements W, Mo, Cr, Ta and V form the straight line of refractory metals (SLRM) of bcc structure. The elements $\mathrm{Be}, \mathrm{Ni}, \mathrm{Co}, \mathrm{Fe}, \mathrm{Si}$ and $\mathrm{Cu}$ are located at the edge of the distribution of elements toward the open space of the diagram. They form a gulf shape, therefore they will be referred to as the "gulf elements" hereafter. It will be shown that they have the unique properties commonly.

\section{Properties of the Gulf Elements}

The properties of the gulf elements can be described comparing with those of other elements as follows:

\subsection{Melting Temperature}

The distribution of the melting temperatures on the TC-YM diagram is shown in Figure 3.

The figures in the legend show the temperature range of melting temperature in Kelvin. W, the element with highest melting temperature, is located at the top of the SLRM. The elements on the SLRM, W, Mo, Cr, Ta and V have high melting temperatures. Fe is located near the SLRM, and is located nearer to Ni than to Cr. Ni has lower melting temperature than $\mathrm{Cr}$, therefore, Fe becomes to have as low melting temperature as Ni. Same thing can be said in the case of Co. This is the reason why the elements Fe and Co have relatively low melting temperatures. 


\subsection{Thermal Expansion Coefficient}

Thermal expansion coefficients also show the similar trend as melting temperatures. The distribution of the thermal expansion coefficient of elements is shown in Figure 4. The gulf elements $\mathrm{Be}, \mathrm{Ni}, \mathrm{Co}, \mathrm{Fe}$ and $\mathrm{Cu}$ except $\mathrm{Si}$ show the larger thermal expansion than the elements on the SLRM. Si is exceptional in the thermal expansion. Si shows the smallest thermal expansion among the elements. But totally, the elements $\mathrm{Fe}, \mathrm{Ni}$ and Co show the similar thermal expansion as $\mathrm{Au}, \mathrm{Cu}$ and $\mathrm{Ag}$. The considerably large thermal expansion of $\mathrm{Fe}$ is sometimes harmful for the practical use.

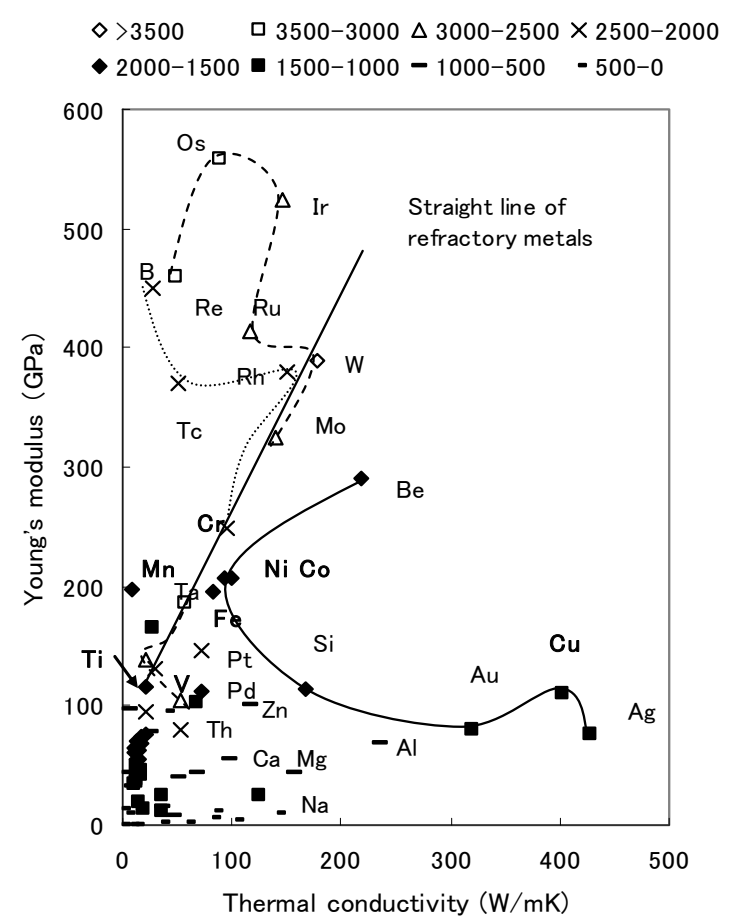

Figure 3. Distribution of the melting temperatures(K) of elements on the TC-YM diagram

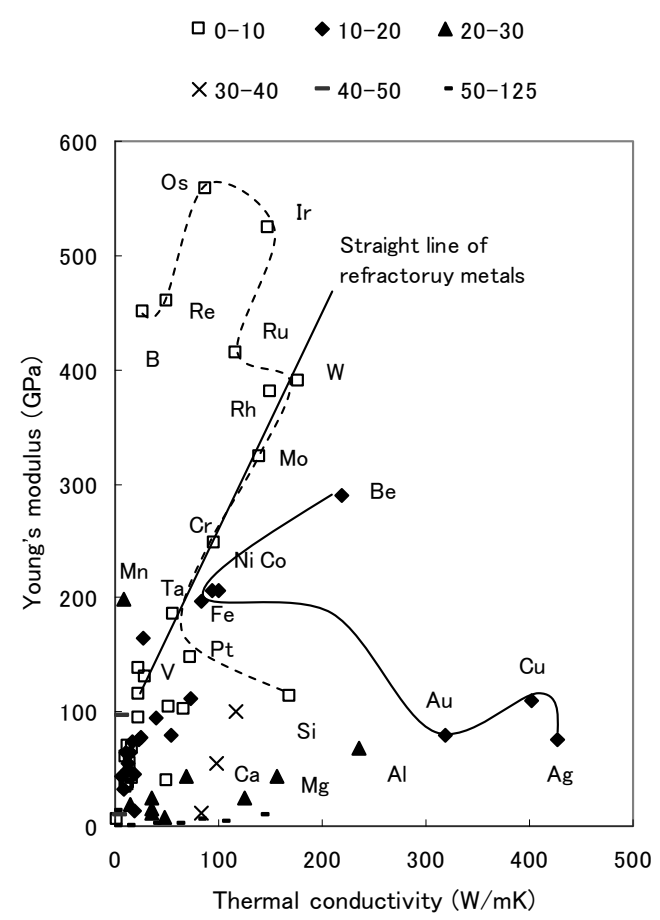

Figure 4. Distribution of the thermal expansion coefficients $\left(10^{-6} / \mathrm{K}\right)$ of elements on the TC-YM diagram

\subsection{Heat of Fusion}

The heats of fusion also show the similar trend as the melting temperature and the thermal expansion. The distribution of the heat of fusion of elements is shown in Figure 5. The gulf elements $\mathrm{Be}, \mathrm{Ni}, \mathrm{Co}, \mathrm{Fe}$ and $\mathrm{Cu}$ except $\mathrm{Si}$ including $\mathrm{Au}$ and $\mathrm{Ag}$ show smaller heats of fusion than the elements on the SLRM. Si is exceptional also in the heat of fusion. Si shows much larger heat of fusion. The considerably small heat of fusion of $\mathrm{Fe}$ is advantageous for the practical use to save fuel.

\subsection{Atomic Radius}

The distribution of the atomic radius of elements is shown in Figure 6. The gulf elements $\mathrm{Be}, \mathrm{Ni}, \mathrm{Co}, \mathrm{Fe}, \mathrm{Si}$ and $\mathrm{Cu}$ including $\mathrm{Cr}$ show the smaller atomic radii than the elements on the SLRM. They have the smallest atomic radii among the metallic elements. It has no practical meaning, but it can be suspected that the gulf elements have essentially the physical meaning. 


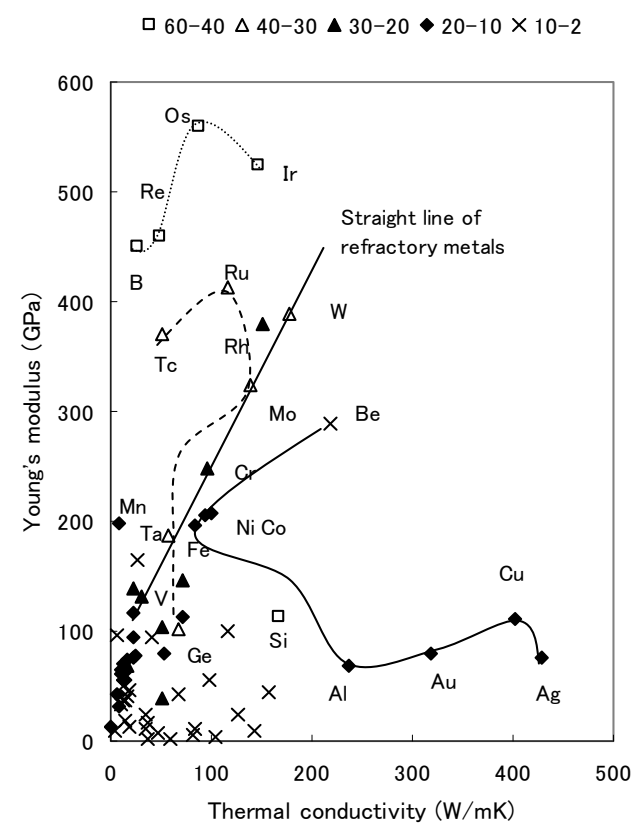

Figure 5. Distribution of the heat of fusion $(\mathrm{kJ} / \mathrm{mol})$ of elements on the TC-YM diagram

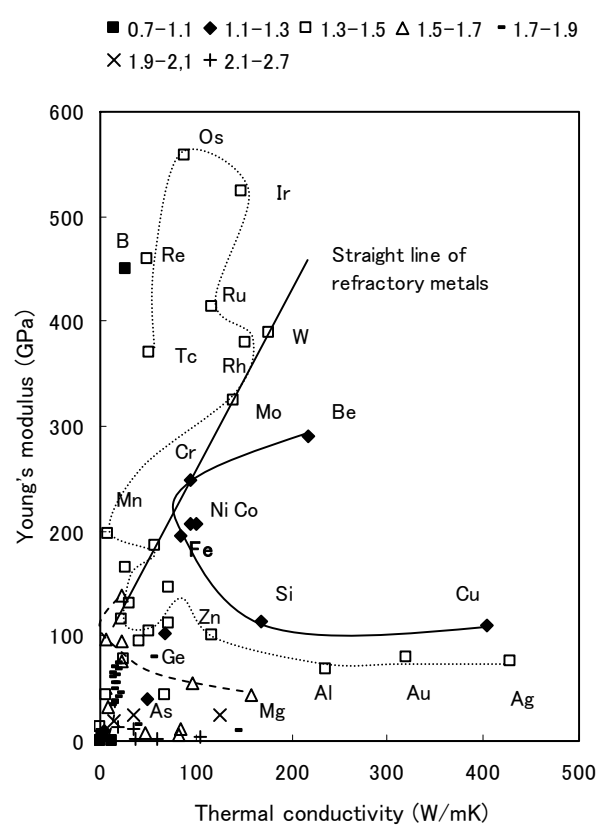

Figure 6. Distribution of the atomic radius $\left(10^{-10} \mathrm{~m}\right)$ of elements on the TC-YM diagram

\subsection{Heat Capacity}

The distribution of the heat capacity of elements is shown in Figure 7. According to the Dulong-Petit law, the heat capacity of elements near room temperature is almost $3 R(24.9 \mathrm{~J} / \mathrm{mol} \mathrm{K})$, regardless of whether they are metals or non-metals (Mizutani, 2001). In fact, the heat capacity of elements varies around $3 R$ among elements. $\mathrm{Be}$ and $\mathrm{Si}$ show the smallest heat capacity among the metallic elements. Fe belongs to the element group of the medium heat capacity.

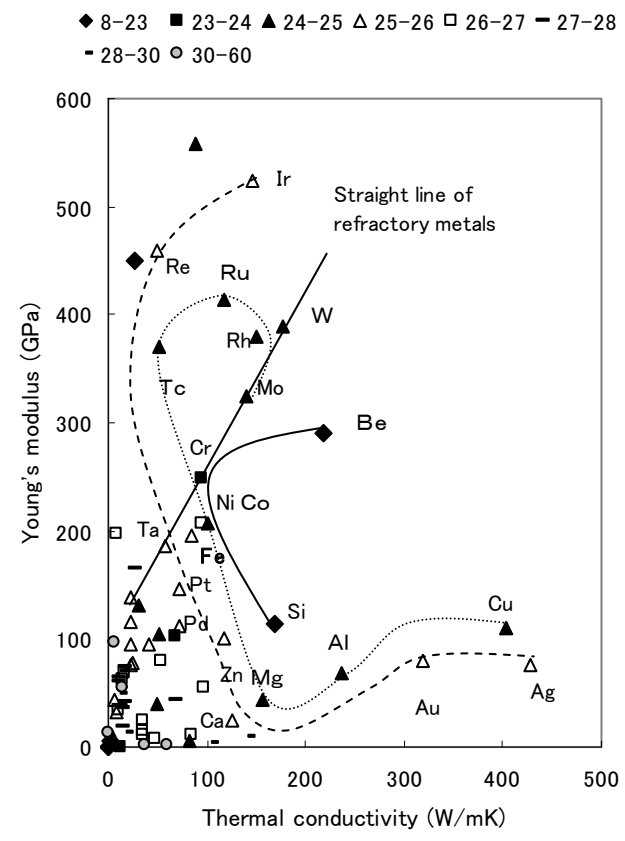

Figure 7. Distribution of heat capacity ( $\mathrm{J} / \mathrm{mol} \mathrm{K})$ of elements on the TC-YM diagram 


\section{Discussion}

The melting temperature of $\mathrm{Fe}$ is much lower than $\mathrm{V}$ and $\mathrm{Cr}$ on the SLRM, because it is slightly off the SLRM to the larger thermal conductivity direction on the TC-YM diagram and belongs to the gulf elements. Owing to such a low melting temperature, ancient people could produce the iron metal, though not by melting directly. Does the fact that iron is off the SLRM bring about other merits to the mankind?

\subsection{Transformation}

Figure 8 shows the distribution of crystal structures on the TC-YM diagram. The crystal structures are classified as body-centered- cubic (bcc), face-centered-cubic (fcc), hexagonal-closed-packed (hcp), diamond structure and "others" for miscellaneous structures. The most remarkable feature is that the bcc-structured elements mostly lie on a straight line connecting $\mathrm{V}, \mathrm{Ta}, \mathrm{Cr}$, Mo and $\mathrm{W}$, which can be called the straight line of refractory metals (SLRM). Additionally, elements with fcc structures lie on a curve, which can be called the line of fcc metals. In contrast, bcc-structured alkali metals lie on a curve near the abscissa (the curve of alkali metals). Elements with hcp and other structures are distributed elsewhere. Lanthanides gather tightly in the low Young's modulus and low thermal conductivity region.

Fe is located near the SLRM, therefore it adopts the bec structure at room temperature, affected by the SLRM. But it transforms into the fcc structure at the elevated temperature, because $\mathrm{Fe}$ is considered to be affected by nearby $\mathrm{Ni}$ of the fcc structure. This transformation is a source of the great merits of Fe (Bhadeshia, Honeycombe, 2006). The steel which is a $\mathrm{Fe}$ alloy with carbon transforms into the martensite by the rapid cooling from the austenitic fcc region, which leads to great hardening of steel.

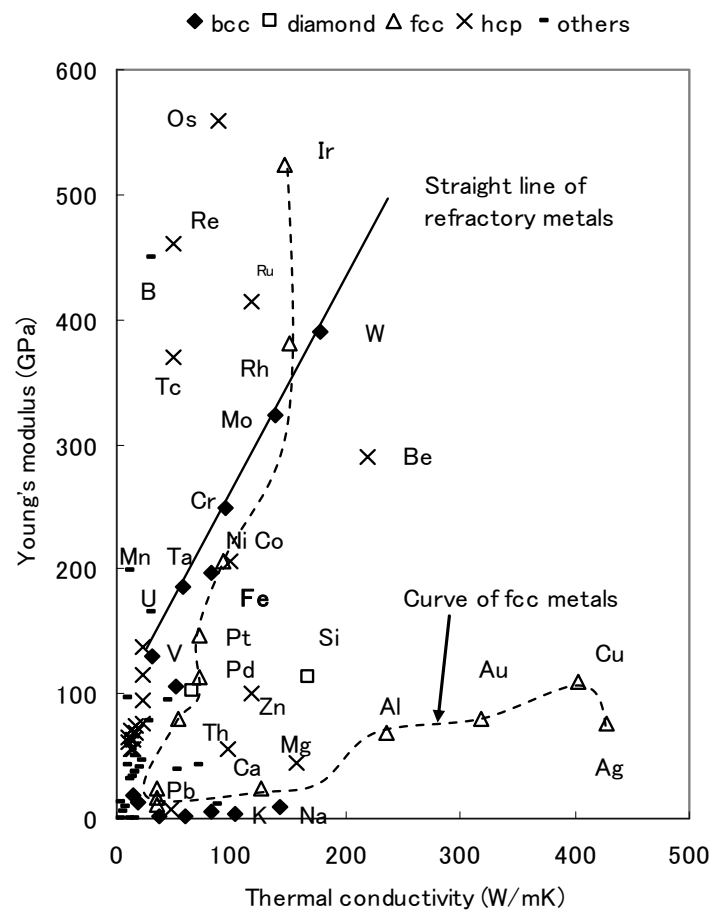

Figure 8. Distribution of the crystal structures of elements on the TC-YM diagram

\subsection{High Young's Modulus and High Thermal Conductivity}

As shown in Figure 2, the gulf elements show a good combination of the thermal conductivity and the Young's modulus. Be has the high Young's modulus and good thermal conductivity. But it adopts a hep structure, because it is located far from both the SLRM and the curve of fcc metals. The metals of hep structures are difficult to be worked due to their limited slip systems. Furthermore, it is toxic. Therefore, $\mathrm{Fe}, \mathrm{Ni}$ and Co become the elements which have the highest Young's modulus and moderate thermal conductivity among the gulf elements. As shown in Figure 9, the high Young's modulus and the high thermal conductivity are advantageous to many properties (Mae, Poonnayom, Wongkrajang, 2009; Mohamed, Murty, Morris, 1973). 


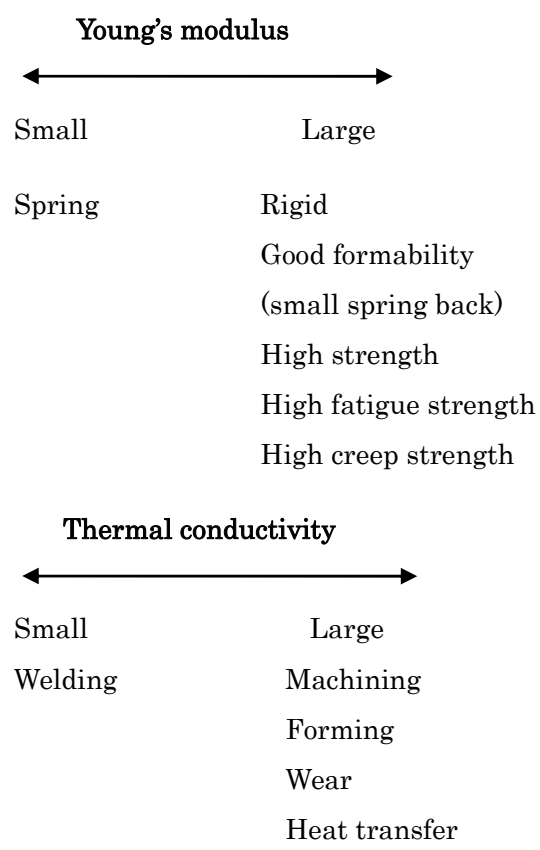

Figure 9. Upper side: The Young's modulus dependence of the material properties Lower side: The thermal conductivity dependence of the material properties

From this point of view, $\mathrm{Fe}$ is a good material for many applications. The Young's moduli and thermal conductivities of the commercial alloys are shown in Figure 10. The alloys of good formability are located in the high Young's modulus and the high thermal conductivity region. For the alloy development, it is important not to lower the thermal conductivity of the alloy.

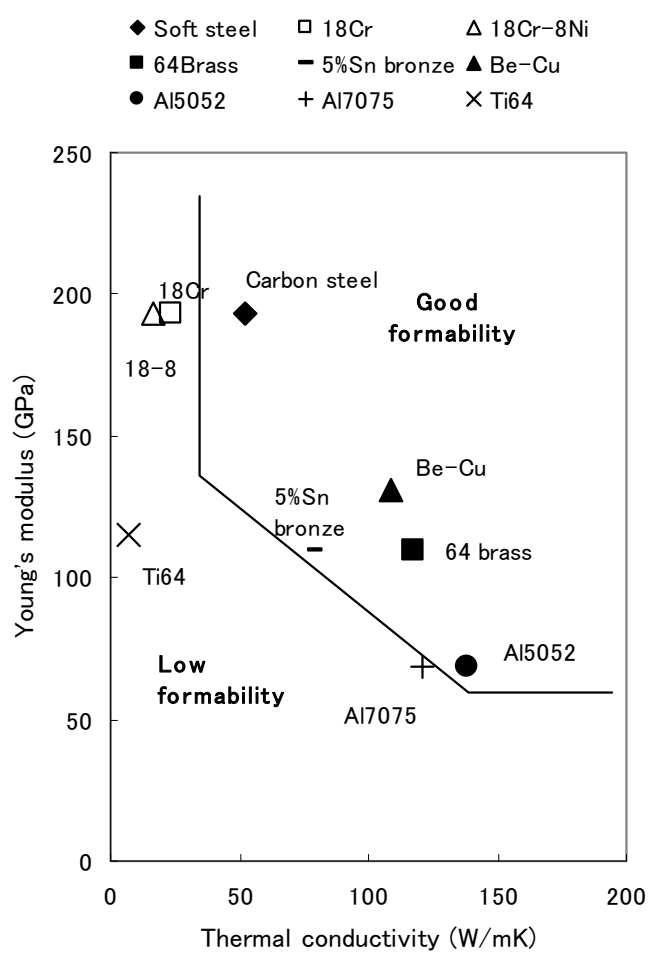

Figure 10. Distribution of the commercial alloys and the boundary between good formability and low formability on the TC-YM diagram 


\subsection{Abundance of Elements}

The element must be abundant in the crust of the earth so that it may be used widely by the humankind. The abundance of elements in the crust is mostly proportional to that in space.

The abundance of elements in space is stated in various literatures (Cherdytsev, 1961; Aller, 1961; Pagel, 2009). Figure 11 shows the distribution of the abundance of elements in space on the TC-YM diagram. The abundance of each element is a value when that of $\mathrm{Si}$ is assumed $10^{6}$. The abundance is expressed by the logarithmic scale here. The elements of the abundance above 4(10000), $\mathrm{Mg}, \mathrm{Si}, \mathrm{Fe}, \mathrm{Al}, \mathrm{Ca}, \mathrm{Na}, \mathrm{Cr}$, and $\mathrm{Mn}$, draw the quadrant on the diagram. The reason why the elements of large abundance draw a quadrant is discussed elsewhere. Figure 12 shows the distribution of the melting temperature of elements where the curve of the elements with the abundance above 4 is superimposed. The elements $\mathrm{Fe}$ and $\mathrm{Si}$ are included in both curves. Figure 12 shows their usefulness owing to the moderate melting temperatures and the large abundances.

\subsection{Ionization Tendency}

Metals must be smelted from the ore easily so that they can be used widely. The ionization tendency is one of the factors which mean the easiness of smelting. The smaller the ionization tendency is, the easier the smelting is. Figure 13 shows the values of ionization tendency $(\mathrm{V})$ of various elements on the TC-YM diagram. $\mathrm{Al}$ and Ti belong to the group of high ionization tendency. Therefore, they are difficult to be smelted from the ore. In contrast, Fe belongs to the group of low ionization tendency. This is a great merit of $\mathrm{Fe}$ for the practical use.

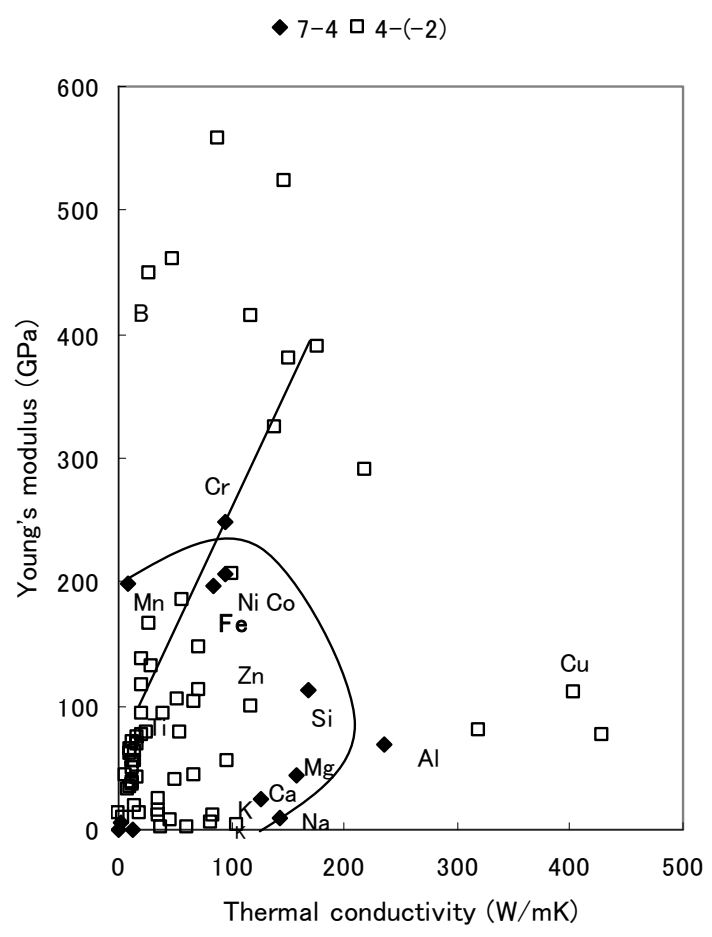

Figure 11. Distribution of the abundance of elements expressed in the logarithmic scale on the TC-YM diagram (the elements with the abundance over 10000 and under 10000)

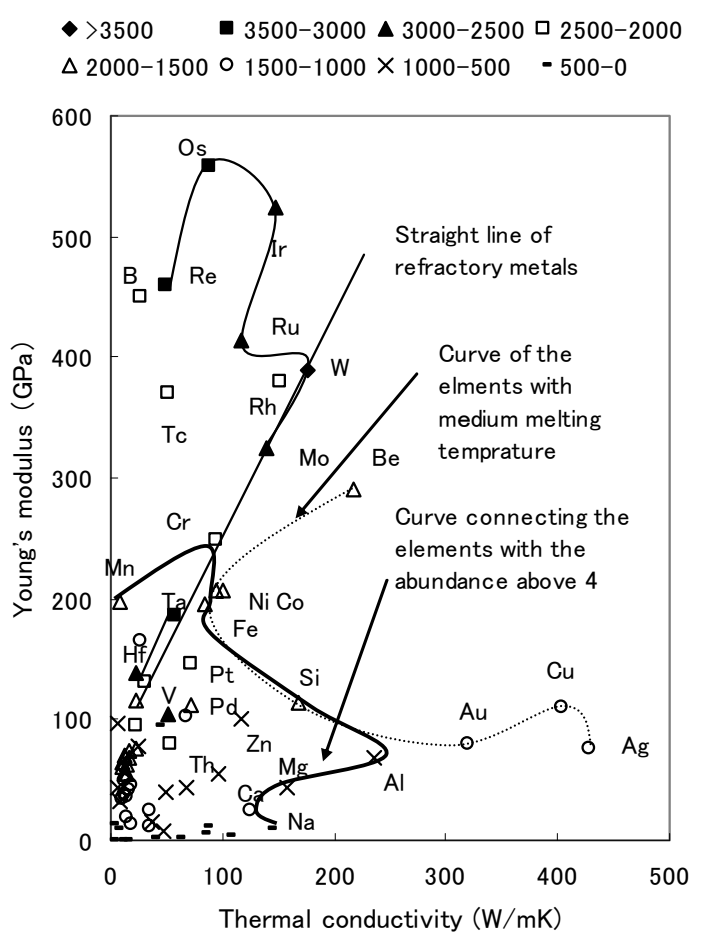

Figure 12. Distribution of the melting temperature of elements where the curve of the elements with the abundance above 4 is superimposed

As mentioned above, the melting temperature of Fe seems to be lowered intentionally when it is observed on the periodic table. This phenomenon is accompanied by the fact that Fe is located slightly off the SLRM toward the larger thermal conductivity direction when it is observed on the TC-YM diagram. As a result, Fe becomes a member of the gulf elements and adopts a relatively low melting temperature. The lowered melting temperature of Fe enabled the ancient people to produce their iron products even by their primitive heating systems. Furthermore, the fact that Fe is slightly off the SLRM toward the increasing thermal conductivity direction is important for other points. If Fe moves largely toward the increasing thermal conductivity direction, it will become to adopt the hcp 
structure like Be. Consequently, its good formability would be lost. Co, which has a little bit larger thermal conductivity than both $\mathrm{Fe}$ and $\mathrm{Ni}$, already adopts hep structure at room temperature, but it transforms into fec at the elevated temperature, affected by $\mathrm{Ni}$, and sustains the formability.

Next, if Fe moves largely toward the increasing thermal conductivity direction, it will also deviate from the quadrant of large abundance. It will damage the low price of the iron products. In addition, Fe is located at the position of low ionization tendency on the TC-YM diagram, which means easiness of smelting. The fact that Fe is located slightly off the SLRM toward the increasing thermal conductivity direction, but not so much as both Ni and $\mathrm{Co}$, seems to be an anthropic principle in Fe.

$\square(-3)-(-2) \Delta(-2)-(-1) \Delta(-1)-0 \square 0-1 \bullet 1-2$

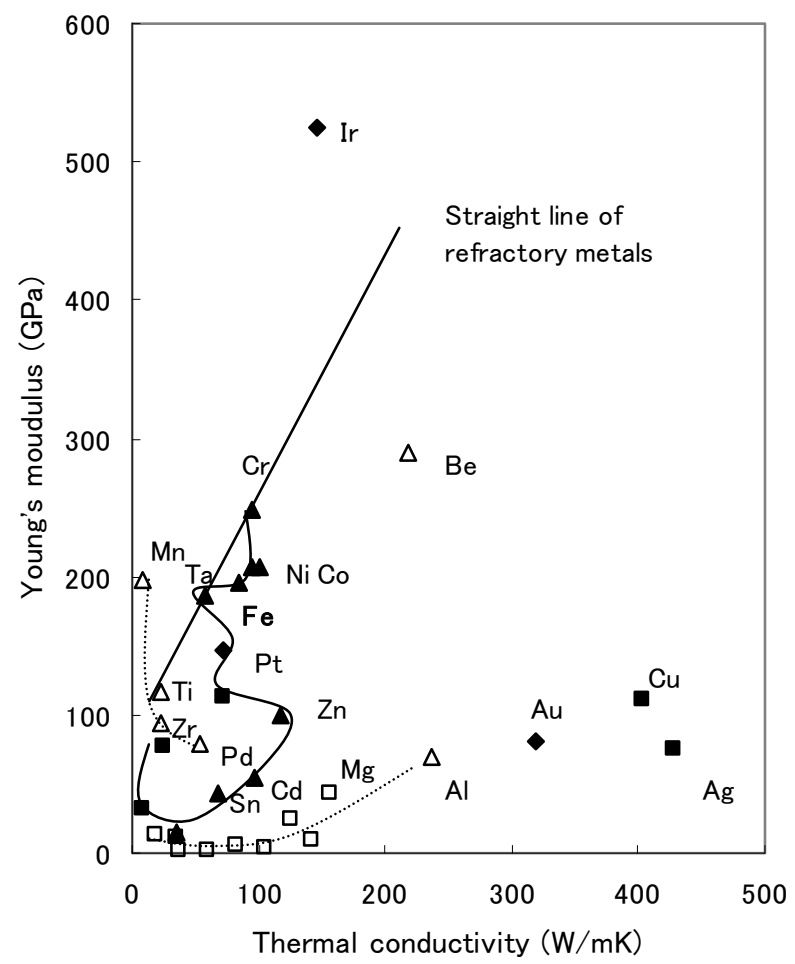

Figure 13. Distribution of the ionization tendency $(\mathrm{V})$ of elements on the TC-YM diagram

\section{Conclusion}

Fe has versatile and useful properties such as a moderate melting temperature, bcc structure at room temperature, fcc structure at the elevated temperature, a moderate combination of the Young's modulus and the thermal conductivity, and a large abundance. They stem from the fact that Fe is located at the narrow position slightly off the straight line of refractory metals (SLRM) toward the larger thermal conductivity on the TC-YM diagram. This may be an anthropic principle in Fe.

\section{References}

Aller, L. H. (1961). The abundance of the elements. New York, NY: Interscience Publishers.

Bhadeshia, H. K. D. H., \& Honeycombe R. W. K. (2006). Steels (3rd Ed.). London: Elsevier.

Cherdyntsev, V, V. (1961). Abundance of chemical elements. Chicago: The university of Chicago press.

Crossman A. (2008). The anthropic principle explained. Retrieved from http://www.allancrossman.com/ap/ amthropic.html

Hayden, W., Moffat, W. G., \& Wulff, J. (1965). The structure and properties of materials: Mechanical behavior. Tokyo: Iwanami.

Hummel, R. F. (1998). Understanding materials science. New York, NY: Springer. 
Mae, Y. (2016). What the Darken-Gurry plot means about the solubility of elements in metals. Metall. Mater. Trans. A, 47, 6498-6506. https://doi.org/10.1007/s11661-016-3730-1

Mae, Y., Poonnayom, P., \& Wongkrajang, A. (2009). Wear mechanism of hot forging die from the viewpoint of diffusion. J.Mater. Eng. Per., 18, 16-20. https://doi.org/10.1007/s11665-008-9257-x

Mizutani, U. (2001). Introduction to the electron theory of metals. Cambridge: Cambridge University Press.

Mohamed, F. A., Murty, K. L., \& Morris, J. W. (1973). Harper-Dorn creep in Al, Pb, and Sn. Metall. Trans, 4, 935-940. https://doi.org/10.1007/BF02645593

Pagel, B. (2009). Nueleopsynthesis and chemical evolution of galaxies. Cambridge: Cambridge University Press.

\section{Copyrights}

Copyright for this article is retained by the author(s), with first publication rights granted to the journal.

This is an open-access article distributed under the terms and conditions of the Creative Commons Attribution license (http://creativecommons.org/licenses/by/4.0/). 